九州大学学術情報リポジトリ

Kyushu University Institutional Repository

Fabrication and Machining of Metal Matrix Composite Using Electric Discharge Machining: A Short Review

Jain, Ankit

Amity University

Cheruku Sandesh Kumar

Amity School of Engineering and Technology

Shrivastava, Yogesh

Galgotias College of Engineering and Technology

https://doi.org/10.5109/4742117

出版情報 : Evergreen. 8 (4)，pp.740-749，2021-12. 九州大学グリーンテクノロジー研究教育センター バージョン:

権利関係 : 


\title{
Fabrication and Machining of Metal Matrix Composite Using Electric Discharge Machining: A Short Review
}

\author{
Ankit Jain ${ }^{1}$, Cheruku Sandesh Kumar², Yogesh Shrivastava ${ }^{3 *}$ \\ ${ }^{1}$ Amity University, Jaipur, Rajasthan, India \\ ${ }^{2}$ Amity School of Engineering and Technology, Jaipur, Rajasthan, India \\ ${ }^{3}$ Galgotias College of Engineering and Technology, Greater Noida, Uttar Pradesh, India. \\ *Author to whom correspondence should be addressed: Yogesh Shrivastava \\ E-mail: yogesh.shrivastava90@gmail.com
}

(Received May 24, 2021; Revised October 20, 2021; accepted October 24, 2021).

\begin{abstract}
Metal Matrix composite is a metal reinforced with two or more constituents which can be any other materials either metal or non-metal. Metal matrix composites (MMCs), which are inherently intelligent, are lightweight and high-performance, ever-expanding materials. The structural and functional properties of these materials may be modified by industrial requirements. Researchers and the industry are attracted by the process technology used in the production and processing of these products. The hybrid-electric discharge process for MMCs is a promising and the most effective nonconventional process. It has greater expertise in manufacturing complex shapes with greater precision. This paper gives an updated analysis of the development and advantages of various routes for composite manufacturing and machining. It reports on several realistic analyzes and study results, including various manufacturing and processing problems for MMC Since the last few years, hybrid electrical discharge machining has been an active field of research in critical and nonconventional machining. This paper includes annual research in production, traditional machining, unconventional machining, and hybrid MMC machining. The final part of the paper addresses conclusions and future scope.
\end{abstract}

Keywords: Metal Matrix Composite, Electric discharge machining, Parameters, Technology, and Composite metal.

\section{Introduction}

The above study is based on the fabrication of the metal in the composition of electric discharge machining. The desired approach of the study is used to evaluate the property of the expansion of thermal materials. The phase of composite material describes the functions on the property of different practices which are supported by the technology of the system. The components of metal matrix composition fabricate the strategy of electric discharge machining. The strength and the models of metal create estimation on the management of thermal expansion. The increased use of the metal describes the function on the phase of the different capabilities of the applications. The average range of the metal generates the function on the need of the metal. The properties of the metal are related to the problems in terms of the fabrication of different metals. There is a performance evaluation of EDC on MMC on the integration of the surfaces.

\subsection{Fabrication of Composite Metal}

The process of fabrication of metal matrix composite depends on the parameters of three states such as solid, liquid, and vapor phase. The composition of the system is used to analyze the estimation based on the distribution of a suitable metal. The state of the liquid phase increases the level of performance on the strategy of the infiltration methods. The matrix system creates a function on the needs of the metals which are used to change the method of the different particles. During the process of the liquid phase, the range of the system provides material based on suitable aspects ${ }^{1-3)}$

\section{Literature Review}

To understand the flow of the literature review, a flowchart has been designed as shown in Figure 1. According to Aharwal and Krishna (2018) ${ }^{4}$, the functions of the particles are used to hold in the position of metal by performing the methods of metal matrix composite i.e. MMC. The fraction of the metal describes the function of the operation of the low concept of viscosity metal. The high cost of operation is suitable in demonstrating the particles of EDM. The fabrication of the metal is decomposed of different particles of the molten matrix to 
modify the different perspectives used in filtering the cost of low fabrication. There are different ranges of fabrication of MMC that are given with the help of the infiltration process. Fabrication of MMC with range by the process of infiltration is indicated in Table 1. As per Patel and Maniya (2018) $)^{5}$, in the given table below, there is a fabrication of a metal matrix composite based on the range of different functions in the process of infiltration. There are three functions of fabrication such as piston, molten metal, and the reform strategy with a suitable range of composition.

Table 1. The constituents of CNG

\begin{tabular}{|c|c|c|}
\hline Sr.No. & $\begin{array}{c}\text { Fabrication of } \\
\text { MMC }\end{array}$ & $\begin{array}{c}\text { Range of MMC by the } \\
\text { process of infiltration }\end{array}$ \\
\hline 1 & Piston & $20-25$ \\
\hline 2 & Molten Metal & $50-75$ \\
\hline 3 & Reform & $81-94$ \\
\hline
\end{tabular}

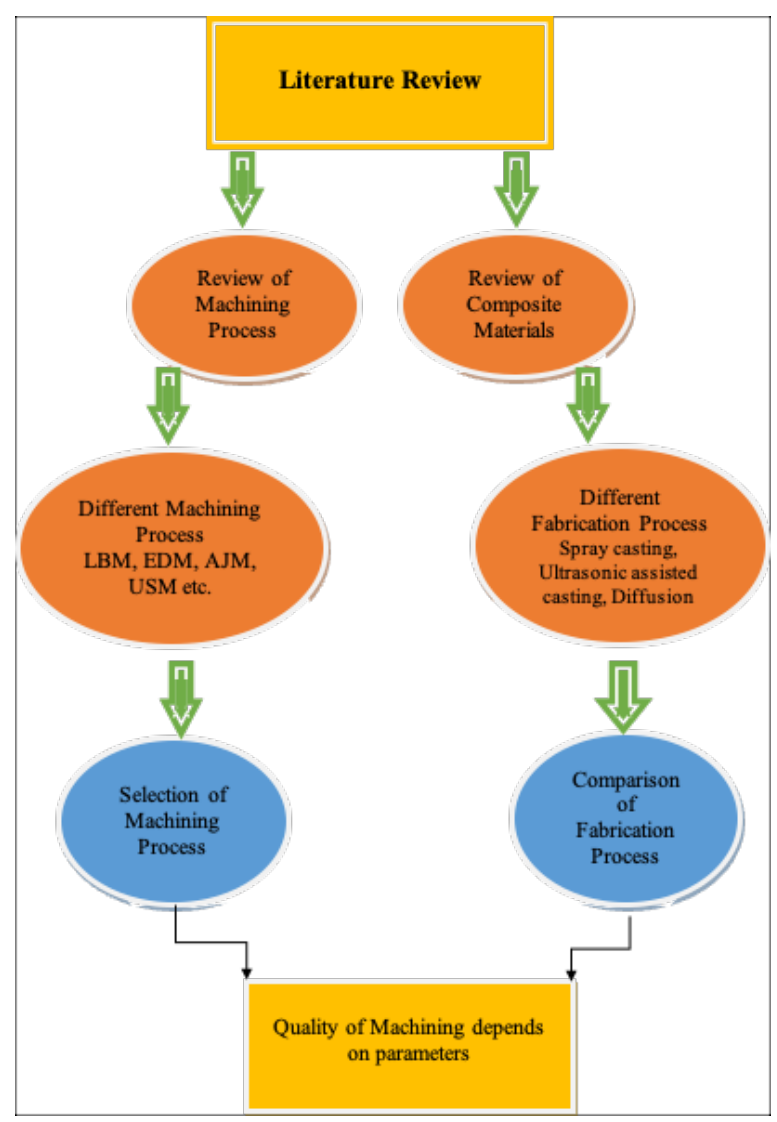

Fig. 1 Flow Chart of the Review process
The range of performance helps in reducing the ability of the system with a function of 20 to $94 \mathrm{C}$. The material of the matrix composite increases the concept of the criteria of different temperatures. The particles are heated on the surfaces of different sequences of operation on the density of the system ${ }^{6-8}$ )

Panwar et al. ${ }^{9}$ stated that the distribution of the system is uniformly spread based on suitable characteristics of the system. The fabrication of metal matrix composite evaluates the presence of different systems on the structure of a suitable crystal. The given diagram of the metal consists of some applications on the solutions of the given system. The exploration of the system helps to manage the functions based on different levels of approaches. The formation of the process is mainly used to describe the factor of suitable functions on the formulation of the metal. The minimum strategy of the process is required to control the overall level of temperatures. Various fabrication methods of MMC are represented in Figure 2.

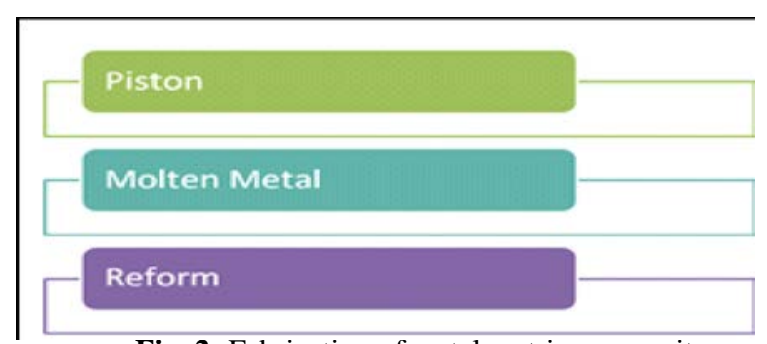

Fig. 2: Fabrication of metal matrix composite

According to Li and Laghari (2019) ${ }^{10)}$, the surface of the molten metal requires a particle on the appearance of the system to examine the different particles of the process. The surfaces of the particles require a function on the method of suitable approach of the study. The stability of the system increases the level of estimation by providing a filter on the range of different approaches. The degradation of the system helps to provide various factors on the property of different interfaces of the metal consisting of various components. The number of different metals describes the properties of the efficiency of the given system ${ }^{11,12)}$. Despite these comparisons between few other fabrication methods are illustrated in table 2.

Table 2. Comparison of different Fabrication processes.

\begin{tabular}{|c|c|c|c|}
\hline Route & Cost & Application & Comments \\
\hline $\begin{array}{c}\text { Spray } \\
\text { casting }\end{array}$ & $\begin{array}{c}\text { Mediu } \\
\mathrm{m}\end{array}$ & $\begin{array}{c}\text { Friction materials, electrical } \\
\text { brushes, and contacts are used in } \\
\text { this process. Cutting and grinding }\end{array}$ & $\begin{array}{c}\text { The reinforcement process is } \\
\text { particulate by this fabrication } \\
\text { method, as well as this method can }\end{array}$ \\
\hline
\end{tabular}




\begin{tabular}{|c|c|c|c|}
\hline & & $\begin{array}{c}\text { tools are a useful component of the } \\
\text { Spray casting method. }\end{array}$ & produce full density materials. \\
\hline $\begin{array}{c}\text { Ultrasoni } \\
\text { c } \\
\text { assisted } \\
\text { casting }\end{array}$ & $\begin{array}{c}\text { Mediu } \\
\mathrm{m}\end{array}$ & $\begin{array}{c}\text { Net-shaped fabrication of metal is } \\
\text { maintained by this fabrication } \\
\text { method. This method is used to } \\
\text { maintain mass production. }\end{array}$ & $\begin{array}{c}\text { The reinforcement process is } \\
\text { particulate by this fabrication } \\
\text { method, as well as this method can } \\
\text { produce full density materials. }\end{array}$ \\
\hline $\begin{array}{c}\text { Diffusion } \\
\text { bonding }\end{array}$ & High & $\begin{array}{c}\text { Sheets, blades, structural } \\
\text { components, and vane shafts are } \\
\text { maintained by Diffusion bonding. }\end{array}$ & $\begin{array}{c}\text { The distribution and good dispersion } \\
\text { of reinforcement particles are } \\
\text { uninformed by this fabrication } \\
\text { method. }\end{array}$ \\
\hline
\end{tabular}

However, Electron discharge machining is a better method of metal matrix composites. EDM can cut the metal in proper shape, which can increase the efficiency of this technology. On the other hand, abrasive reinforcement policies are involved in the EDM process, which can increase the efficiency of these processes. Conventional machining of MMC is maintained with the involvement of this aspect. On the other hand, geometric tolerance of metal is increased with the involvement of EDM. Based on this information it is easy to say that EDM is between that fabrication processes. Moreover, a lot of work has been reported by several researchers in the field of fabrication of different composites including MMC, Fiber-based, and polymers ${ }^{13-27)}$.

\section{Widely used metal matrix composite}

Aluminum MMCs have widely used metal matrix composites. Few important examples of Aluminum metalmatrix composites are aluminum-graphite composite, aluminum-beryllium composites, and others. EDM process is used increasingly to maintain the production of Aluminum metal-matrix composites. EDM is treated as the most widely used non-traditional machining process, as well as EDM is the most important unconventional machining technique. Production of Aluminum MMCs is maintained with the involvement of Wire EDM. EDM is treated as an effective cost-effective process, which is conducted with the involvement of proper machining speed.

\subsection{Performance evaluation of EDM on MMC}

As per Prashanth et al. (2017) ${ }^{28)}$, the concept of electric discharge machining evaluates the criteria of performance on the function of metal matrix composition. The process of EDM generates the functions on the ability of MMC to influence the approach of the study. The demonstration of the process typically examines the material at the rate of electrical properties. The parameters of the properties consist of current, pulse polarity, voltage as well as the variable of different functions. The measurement of the system enhances the mechanisms on the particles of the metal during the functions of the EDM. The composition of the process increases the properties of the metal ${ }^{29-32)}$.

Senthil Kumar and Murali Kannan (2019) ${ }^{33)}$ stated that there is typical reinforcement is used in the composition of a metal matrix approach to analyze the functions of the system. The affection of the EDM process evaporates the functions on the matrix of suitable particles. The expansion of the composite materials contributes to the factor of different approaches on the analysis of suitable methods. The different surfaces of MMC indicate the parameters based on the effect of current and pulse polarity. The machining process of particles affects the dimensions of the system to enhance the approaches of the process. The reduction of the different parameters is used in the postulates of reinforcement strategy $y^{9,34,35)}$

The given table 3 shows reinforcements that are used in the composition of metal matrix analysis based on the aspect ratio of the metal.

Table 3. Comparison of different metals with their aspect's ratio and diameter.

\begin{tabular}{|c|c|c|c|}
\hline $\begin{array}{c}\text { The strategy of } \\
\text { the metal }\end{array}$ & $\begin{array}{c}\text { Aspects } \\
\text { Ratio }\end{array}$ & Diameter & $\begin{array}{c}\text { Different } \\
\text { examples }\end{array}$ \\
\hline Particle & $1-2$ & $1-25 \mathrm{~nm}$ & Sic, WC \\
\hline Short fiber & $10-1000$ & $1-5 \mathrm{~nm}$ & $\mathrm{C}, \mathrm{Al} 2 \mathrm{O} 3$ \\
\hline $\begin{array}{c}\text { Continuous } \\
\text { Fiber }\end{array}$ & $>10000$ & $<100 \mathrm{~nm}$ & $\mathrm{Nb}+\mathrm{Ti}$ \\
\hline
\end{tabular}

According to Yang et al. (2020) ${ }^{36}$, the strategy of the metal consists of some aspect ratios based on the diameter of different ranges of the metal matrix. The functions of the particle, short fiber, and continuous fiber consist of different terms based on the approach of suitable estimation. The percentage of the given metal evaluates the composition between the factors to increase the overall strategy of the system. The contents of Al2O3 investigate the effect on the function of current, voltage, and the polarity of the pulse. The different variation of the material helps to remove the rate of functions by 
increasing the efficiency of the pressure.

As per Wang et al. (2017) $)^{37)}$, the amount of different materials reduces the density of electric discharge machining on the ability of MMC. The overall formulation of the system depends on the intensity of the system by creating a huge amount of information. The concept of EDM rapidly evaluates the performance on the contribution of the different materials. The amount of metal has significantly analyzed the approaches to decrease the accuracy of the process. The efficiency of the metal relates to the process of development by analyzing the machining parameter of EDM. The optimization of $\mathrm{Al} 203$ and SiC provides a complexity to propagate the given network ${ }^{38,39)}$.

\subsection{EDM surface integrity}

Qudeiri et al. (2020) ${ }^{40)}$ stated that the integration of electric discharge machining i.e. EDM surfaces evaluates the functions on the factors of different aspects of the system. The components of the different metal matrices are used to observe the functions to optimize the efficiency of the process. The parameters of EDM create a layer to minimize the functions of the overall system. The different machining surfaces of EDM helps to integrate the context of a metal matrix based on the technique of different parameters. The components of the given surfaces consist of some layer that generally occurs to transfer the methods of integration ${ }^{41-43)}$.

There are three distinct surfaces used that help to reveal the approach of suitable methods of the functions. The property of the EDM surface integrity affects the criteria to increase the level of enhancement. The different layers of machined surfaces such as recast layer, HAZ i.e., heat affected zone layer, and converted layer. The functions of the given layer create a factor of decomposition based on the amount of metal that is used in the transmission strategy. The concept of recast increases the surfaces of molten metal with an insufficient amount of transmission $^{44-46)}$.

Khosrozadeh and Shabgard (2017) ${ }^{47)}$ stated that the medium of different EDM surfaces is used to increase the process on the ability of the system which is used to increase the level of estimation on the strategy of the system. The characteristics of the given structure evaluate the functions in terms of the decomposition of molten metal. The portion of the matrix increases the rate of evaluation which are consists of suitable approaches. Figure 3 shows the different layers of EDM surface integrity. The different layers of the given process estimate the concept of pulse and current which are carried out to change the methods of EDM. The consequences of the system are used to cause the method on the approach of suitable estimation ${ }^{48-50)}$.

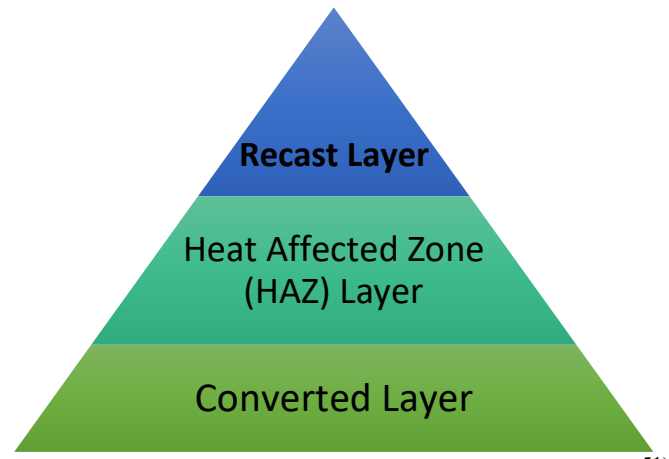

Fig. 3: Different layers of EDM surface integrity ${ }^{51)}$

According to Liu et al. (2019) ${ }^{52)}$, the performance of the EDM has a vast impact on the tools of a standard electrode to obtain a desired amount of evaluation. The parameters of the process are used in the factor of predominant functions which are resulted in the integrity of machining. The speed of electrodes generally helps in combining the system on a wide range of machining parameters. The chemical composition of EDM is developed in the process of different methods which are used to reduce the functions of the given process. In the given pie chart, there is a function of EDM on the different contexts of MMC.

\section{EDM Surface Integrity on MMC}

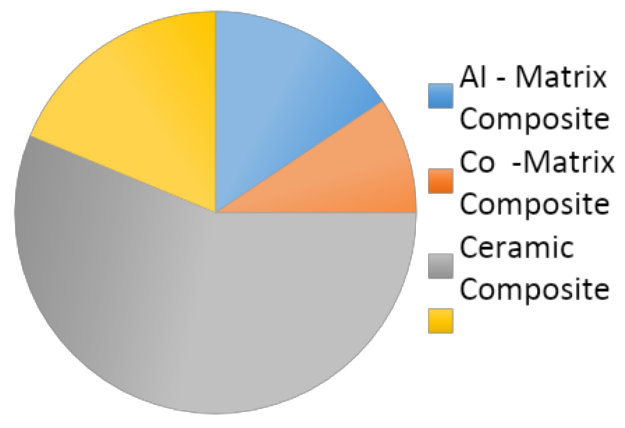

Fig. 4: Electric discharge machining surface integrity on Metal matrix composite ${ }^{53)}$

As per Holmberg et al. (2018) ${ }^{53)}$, the machining of the process enhances the strength of the system based on the contribution of different ranges. Electric discharge machining consists of some matrix composite on the different perspectives of the elements. There is $18 \%$ of $\mathrm{Al}-$ matrix composite, $7 \%$ of Co-Matrix composite, $60 \%$ of ceramic composite, and $15 \%$ of Hybrid composite are used. Figure 4 shows the Surface integrity on MMC by Electric discharge machining.

\subsection{Residual Stresses}

The uneven solidification of the molten metal results in residual stress which is a kind of defect found during electric discharge machining. According to Liu et al. $(2018)^{52)}$, these defects can be the reason for failure or cause corrosion during the tensile loading. The exceeding of the ultimate strength of the materials by the induced residual stress comes as a failure can be shown in the form 
of cracks. The designers got attracted towards the residual stress due to the heavy structure of the sudden collapse of a bridge in Belgium in the year 1938, March ${ }^{54)}$. It was found the collapse was produced due to a welding process which results in residual stress and is shown in the form of crack. The crack became the reason for failure due to its extension to the base metal. During the electrical discharge machining, the same kind of failures was observed that happened to residual stress.

The surface integrity gets affected due to various electric and non-electric parameters. These parameters include peak current, material properties of electrodes that contain the workplace as well as tools, pulse durations, voltage, dielectric effect, and polarity. According to Casavola et al. $(2017)^{55)}$, the early failure of the structure can be easily detected by using surface integrity and it is used by the researchers in the area of non-destructive testing methods. One of the most popular destructive techniques is known as X-ray diffraction whose resolution is about 20um vertically and $1 \mathrm{~mm}$ in-plane. The neutron diffraction penetration is found in $\mathrm{Ai}$ about $20 \mathrm{~mm}$ and in $\mathrm{Ti} 4 \mathrm{~mm}$ with a resolution of 500um. The penetration of ultrasonic is greater than $10 \mathrm{~cm}$ and the resolution is about $5 \mathrm{~mm}$. The penetration of passive magnetic techniques found penetration of about $20 \mathrm{~mm}$ and a resolution of $1 \mathrm{~mm}$. Eddy current techniques and active magnetic techniques also have penetration of $1 \mathrm{~mm} \mathrm{~mm}$ and resolution of $1 \mathrm{~mm}^{56)}$

The effect of the residual stress on the surface integrity and fatigue life has been explained in the research. The recent advancement in measuring tools has been also found in the research. The evaluation of the residual stress in the ED machine has not been found yet figure 5 shows the Residual Stress Variation. The bending deflection was used for measuring the residual stress in the EDM. According to Honnige et al. (2018) ${ }^{57)}$, the measuring of the residual stress in the EDM gave the results that the maximum value of the residual stress and tensile should be below the machined surface and as the discharge energy varies, then the magnitude and depth of the residual stress will also vary accordingly. In the ED machine steel, some of the researchers used X-ray diffraction.

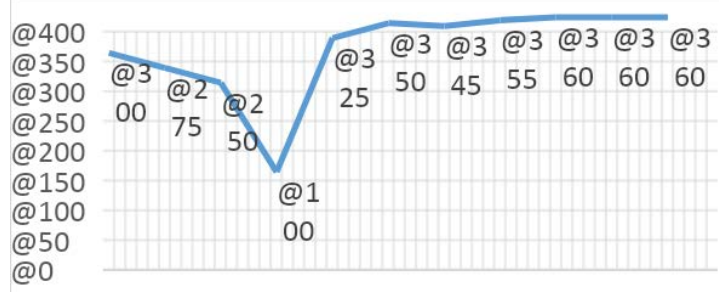

$0 \quad 50100150200250300350400450500$

— Resuidal Stress

Fig. 5: Residual Stress Variation ${ }^{58)}$

\section{Overview of Electric discharge machining}

Electric discharge machining methods are used to overcome the problems with the traditional machining methods. According to Syed et al. (2019) ${ }^{59)}$, traditional machining methods get failure after some limitations and cannot give high accuracy to the materials. Electrical Discharge Machining is applicable for all the conductive materials and provides high accuracy to them. Thermal energy is used in electrical discharge machining to remove the materials from the workpiece. Mechanical force is not required in the EDM for the removing process such as laser cutting. EDM is considered as non-traditional contrary as it does not require any mechanical force for the cutting process as like the traditional methods required ${ }^{60-62)}$. EDM is widely used in the field of tool and molding making as it can be easily applicable for hard materials such as titanium. The EDM can be used to achieve complex shapes which cannot be achieved through milling.

Electrical Discharging Machining is a nonconventional electro thermal machining process where an electrical spark is generated through the electrical energy and thermal energy of the spark is used to remove the materials. The high resistant alloys and difficult-tomachine materials used EDM for removing the metals from the theme. Electrically conductive in EDM is done through Work material. Four basic components of EDM include pulse power supply system, electrode feeding system, dielectric supply system, and electrode and the workpiece $^{63-65)}$. There is no direct connection made between the electrode and the workpiece in the EDM due to which it reduces the vibration problem and mechanical stress chatter during machining.

Metal is removed by using the EVL through the electric spark erosion. Electric Discharge Machining used an electric spark as a cutting tool to cut the material and act as an erode from the workpiece and produced a desirable well-furnished shape. The process of removing the metal from the materials in EDM is done by pulsating the electrical charge through the electrode with high frequency to the workpiece. Various types of EDM are used for removing metals from materials. Sinker EDM, Wire EDM, and hole drilling EDM are the types of EDM used for removing metals from materials. Sinker EDM is used for producing complex shapes by removing metals. In the sinker EDM electrodes are made from graphite to produce shape by sinking into the workpiece.

Wire EDM is used for cutting the workpiece and the wires act as electrodes. In the wire EDM, the spool is used for bringing the wire constantly from the automated feed during the period of machining. According to Kumar et al. $(2018)^{7}$ ), whole drilling EDM is used for drilling the holes and compared to the traditional drilling techniques this method can produce deep and extremely small-sized holes. The holes which are done through the hole drilling EDM don't require any deburring. The Use of EDM offers various advantages as the first advantage is that it can be used on all types of materials. The second advantage of using EDM is that it can be used on the hardest materials as the workpiece used in the EDM is titanium which allows it to provide any shape to the materials. The normal cutting tools do not allow producing certain shapes and 
depths as they can produce some limited shapes and depth.

\subsection{Working principle of EDM}

Electrical Discharge Machining provides the desired shape to the workpiece by generating sparks through discharge ${ }^{66)}$. Two electrodes are separated through the dielectric liquid and a voltage is applied to produce a periodic and fast-changing current to remove the metals from the materials. The two electrodes are known as pole head or tool electrode and the other electrode is known as a workpiece electrode. During the whole process, there is no connection between both electrodes. Molybdenum and copper wires are the main wire cutting materials used as electrodes and the products and the electrode starters corroded at the same time ${ }^{67,68)}$.

The degree of corrosion is smaller in electrodes as compared to the products. Liquid coolant acts as a discharge medium which is used for cooling the materials during the processing. Pulse voltage is used between both electrodes and creates a proper gap between both electrodes.

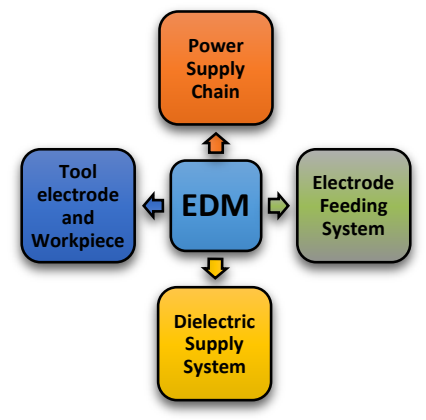

Fig. 6: Basic Components of EDM ${ }^{69)}$

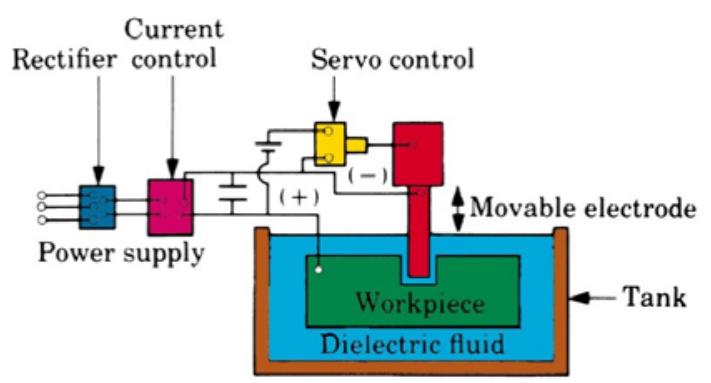

Fig. 7 Shows a schematic diagram

Figure 6 shows the basic components of EDM and Figure 7 shows a schematic diagram. The medium between both electrodes gets broken by the current which results in the appearance of the discharge channel. The high temperature will be generated by the discharge channel which leads to melting the workpiece. A huge electrical pit appears and the electrode returns to a safe distance after completion of one $\mathrm{EDM}^{70-72)}$.

\subsection{Parameters of the EDM process}

The EDM process involves two kinds of parameters known as process parameters and response parameters. In the process parameters, two kinds of variables are present which include the electrical parameters and non-electrical process parameters where the response parameters include only dependent parameters. The electrical parameters of the process parameters include electrode gap, pulse duration, pulse interval, and duty cycles. During the process of EDM, there is a gap between the electrode and the remaining part, and that remaining part is known as the electrode gap. In response to average gap voltage, hydraulic systems or electro-mechanical systems are used. According to Kou and Han $(2018)^{73)}$, it is needed to maintain a suitable gap for providing stability to the gap and this also helps in obtaining good performance. This will help to get the accurate shape with well finishing of the materials ${ }^{74)}$. To fix the problem of short circuits it is needed to have high speed. The average gap is used to measure the gap width. The electrode gap is also known as the spark gap. Pulse duration is the time that is measured in the microseconds and it is also known and pulse on times. Figure 6 shows the Pulse waveform of the pulse generator. The wear behavior of the electrode is affected by the machined areas which get improved by the longer purse duration ${ }^{76)}$.

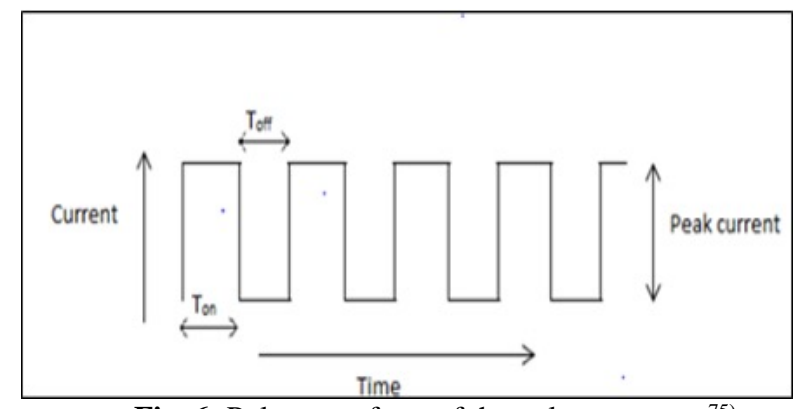

Fig. 6: Pulse waveform of the pulse generator ${ }^{75)}$.

The amount of energy applied during the on-time period is directly proportional to the metal removal. Pulse interval is the condition where the material does not find any machining and the metal from the materials gets vaporized from the setting. The MRR time gets decreased with the increment in the pulse interval. The stability and speed of the cut are affected by the pulse interval. The percentage between the on-time relative with the total cycle time is known as the duty cycle. The duty cycle indicates the degree of efficiency of operation. Table 4 shows the process parameters and response parameters.

Table 4. Process parameters with their response parameters

\begin{tabular}{|c|c|}
\hline Process Parameters & Response Parameters \\
\hline Electrical Parameters & MRR (Material Removal \\
Electrode gap & rate \\
Pulse duration & TWR (Tool Wear rate \\
Duty cycle & RCL (Recast layer) \\
Pulse interval & SR (Surface Roughness) \\
Non-electric parameters & Taper and overcut \\
Workpiece rotation & HAZ (Heat Affected Zone) \\
Flushing of dielectric fluid & \\
Electrode rotation & \\
\hline
\end{tabular}

Non-electrical parameters consist of workpiece rotation, flushing of dielectric fluid, and electrode rotation. The performance measure can be optimized by 
using non-electrical parameters. The flushing of dielectric acts as a coolant and affects the SR and TWR. By using the flushing, the debris can be flushing away from the mechanical group. The crack density and the recast layer are influenced by the flushing pressures. The circulation of the dielectric fluid is improved through the workpiece rotary motion ${ }^{36)}$.

\section{Conclusion}

The present work illustrates the findings and research done in the field of metal matrix composite, considering the fabrication and machining of hybrids using EDM. The key findings of the work have been listed below:

- The need for advanced hard materials for industrial applications also creates scope for preparing new hybrids with enhanced mechanical properties.

- The difficult-to-cut hard materials, specifically composites are always treated and point of research for being machined. A lot of unconventional machining processes are available for the machining of such composites.

- Comparing the available machining processes, EDM stands with more benefits in terms of preserving material properties with precise cut quality.

- Moreover, the selection of correct input parameters and machine settings usually affects the performance and quality of the EDM. Hence, the selection of appropriate machining parameters and levels plays an important role in achieving optimized quality.

- Considering the disadvantages of EDM, as the EDM process uses thermal energy and reduces mechanical forces for removing the material, few deficiencies are also present in the EDM process.

- Additional time and costs are effective disadvantages of the EDM machining process. Due to the presence of electrode wear, it is tough to produce sharp concern, which can decrease the efficiency of the EDM process.

- On the other hand, the slow rate of material removal directly has an impact on the efficiency of the Electrical Discharge Machining Process.

\section{References}

1) Chinmayee Kar, B Surekha, Hemalatha Jena, and Suvan Dev Choudhury, "Study of Influence of Process Parameters in Electric Discharge Machining of Aluminum-Red Mud Metal Matrix Composite", Procedia Manufacturing, 20 392-99 (2018).

2) Alokesh Pramanik, Mohammad Nazrul Islam, Brian Boswell, Animesh K Basak, Yu Dong, and Guy Littlefair, "Accuracy and Finish During Wire Electric Discharge Machining of Metal Matrix Composites for Different Reinforcement Size and Machining Conditions", Proceedings of the Institution of Mechanical Engineers, Part B: Journal of Engineering Manufacture, 232 (6) 1068-78 (2018).

3) Sachin Mohal, and Harmesh Kumar, "Parametric Optimization of Multiwalled Carbon Nanotube-
Assisted Electric Discharge Machining of Al-10\% Sicp Metal Matrix Composite by Response Surface Methodology", Materials and Manufacturing Processes, 32 (3) 263-73 (2017).

4) KR Aharwal, and CM Krishna, "Optimization of Material Removal Rate and Surface Roughness in Edm Machining of Metal Matrix Composite Using Genetic Algorithm", Materials Today: Proceedings, 5 (2) 5391-97 (2018).

5) Jaksan D Patel, and Kalpesh D Maniya, "A Review On: Wire Cut Electrical Discharge Machining Process for Metal Matrix Composite", Procedia Manufacturing, 20 253-58 (2018).

6) Avijeet Satpathy, S Tripathy, N Pallavi Senapati, and Mihir Kumar Brahma, "Optimization of Edm Process Parameters for Alsic-20\% Sic Reinforced Metal Matrix Composite with Multi Response Using Topsis", Materials Today: Proceedings, 4 (2) 304352 (2017).

7) Ravinder Kumar, Ankita Kumar, and Inderdeep Singh, "Electric Discharge Drilling of Micro Holes in Cfrp Laminates", Journal of Materials Processing Technology, 259 150-58 (2018).

8) D Pritima, J Vairamuthu, P Gopi Krishnan, S Marichamy, B Stalin, and S Sheeba Rani, "Response Analysis on Synthesized Aluminium-Scandium Metal Matrix Composite Using Unconventional Machining Processes", Materials Today: Proceedings, 33 4431-35 (2020).

9) Narender Panwar, and Amit Chauhan, "Fabrication Methods of Particulate Reinforced Aluminium Metal Matrix Composite-a Review", Materials Today: Proceedings, 5 (2) 5933-39 (2018).

10) Jianguang Li, and Rashid Ali Laghari, "A Review on Machining and Optimization of Particle-Reinforced Metal Matrix Composites", The International Journal of Advanced Manufacturing Technology, 100 (9) 2929-43 (2019).

11) Bhaskar Chandra Kandpal, Jatinder Kumar, and Hari Singh, "Optimisation of Process Parameters of Electrical Discharge Machining of Fabricated Aa 6061/10\% Al2 O3 Aluminium Based Metal Matrix Composite", Materials Today: Proceedings, 5 (2) 4413-20 (2018).

12) Şener Karabulut, Halil Karakoç, and Ramazan Çitak, 'Effect of the B4c Reinforcement Ratio on Surface Roughness of A16061 Based Metal Matrix Composite in Wire-Edm Machining', in 2017 8th International Conference on Mechanical and Aerospace Engineering (ICMAE) (IEEE, 2017), pp. 812-15.

13) Prakash Dwivedi, Manish Maurya, Kumar Maurya, Kumar Srivastava, Satpal Sharma, and Ambuj Saxena, "Utilization of Groundnut Shell as Reinforcement in Development of Aluminum Based Composite to Reduce Environment Pollution: A Review", EVERGREEN Joint Journal of Novel Carbon 
Resource Sciences \& Green Asia Strategy, 7 (01) 1525 (2020).

14) Manish Maurya, Nagendra Kumar Maurya, and Vivek Bajpai, "Effect of Sic Reinforced Particle Parameters in the Development of Aluminium Based Metal Matrix Composite", EVERGREEN Joint Journal of Novel Carbon Resource Sciences \& Green Asia Strategy, 6 (3) 200-06 (2019).

15) Shashi Prakash Dwivedi, Nagendra Kumar Maurya, and Manish Maurya, "Assessment of Hardness on Aa2014/Eggshell Composite Produced Via Electromagnetic Stir Casting Method", Evergreen Joint Journal of Novel Carbon Resource Sciences \& Green Asia Strategy, 6 (4) 284-94 (2019).

16) $P$ Wahyu Raharjo, Rudy Soenoko, Anindito Purnowidodo, and Agus Choiron, "Characterization of Sodium Bicarbonate Treated Zalacca Fibers as Composite Reinforcements", Evergreen, 6 (1) 29-38 (2019).

17) Endah R Dyartanti, I Nyoman Widiasa, Agus Purwanto, and Heru Susanto, "Nanocomposite Polymer Electrolytes in Pvdf/Zno Membranes Modified with Pvp for Lifepo_4 Batteries", Evergreen, 5 (2) 19-25 (2018).

18) Hiroshi Naragino, Mohamed Egiza, Aki Tominaga, Koki Murasawa, Hidenobu Gonda, Masatoshi Sakurai, and Tsuyoshi Yoshitake, "Fabrication of Ultrananocrystalline Diamond/Nonhydrogenated Amorphous Carbon Composite Films for Hard Coating by Coaxial Arc Plasma Deposition", EVERGREEN Joint Journal of Novel Carbon Resource Sciences \& Green Asia Strategy, 3 (01) 15 (2016).

19) Mohamed Egiza, Hiroshi Naragino, Aki Tominaga, Kouki Murasawa, Hidenobu Gonda, Masatoshi Sakurai, and Tsuyoshi Yoshitake, "Si and Cr Doping Effects on Growth and Mechanical Properties of Ultrananocrystalline Diamond/Amor-Phous Carbon Composite Films Deposited on Cemented Carbide Substrates by Coaxial Arc Plasma Deposition", Evergreen: joint journal of Novel Carbon Resource Sciences \& Green Asia Strategy, 3 (1) 32-36 (2016).

20) Ashish Kumar Srivastava, Shashi Prakash Dwivedi, Nagendra Kumar Maurya, and Manish Maurya, "3d Visualization and Topographical Analysis in Turning of Hybrid Mmc by Cnc Lathe Sprint 16tc Made of Batliboi", Evergreen, 7 (2) 202-08 (2020).

21) Dharu Feby Smaradhana, Dody Ariawan, and Rafli Alnursyah, "A Progress on Nanocellulose as Binders for Loose Natural Fibres", Evergreen, 7 (3) 436-43 (2020).

22) Sarower Kabir, Faiz Ahmad, Khurshid Malik, Norlin Nosbi, and Laurent GUI LLAUMAT, "Effect of Heat Resistant Coating on the Drilled Hole Quality of Hybrid Fiber Reinforced Epoxy Composite", (2020).

23) Anusha Leemsuthep, Zunaida Zakaria, Varaporn Tanrattanakul, Du Ngoc, and Uy Lan, "Formation of
Porous Epoxy Micro-Beads from a Single Droplet of Epoxy-Polyamide-Ammonium Bicarbonate at Different Temperatures".

24) Nagendra Kumar Maurya, Vikas Rastogi, and Pushpendra Singh, "Experimental and Computational Investigation on Mechanical Properties of Reinforced Additive Manufactured Component", EVERGREEN Joint Journal of Novel Carbon Resource Sciences \& Green Asia Strategy, 6 (03) (2019).

25) Ang Li, Azhar Bin Ismail, Kyaw Thu, Muhammad Wakil Shahzad, Kim Choon Ng, and Bidyut Baran Saha, "Formulation of Water Equilibrium Uptakes on Silica Gel and Ferroaluminophosphate Zeolite for Adsorption Cooling and Desalination Applications", Evergreen, 1 (2) 37-45 (2014).

26) Jabir Al Salami, Changhong Hu, and Kazuaki Hanada, 'A Study on Smoothed Particle Hydrodynamics for Liquid Metal Flow Simulation' (Kyushu University, 2019).

27) Matheus Randy Prabowo, Almira Praza Rachmadian, Nur Fatiha Ghazalli, and Hendrik O Lintang, "Chemosensor of Gold (I) 4-(3, 5-Dimethoxybenzyl)3, 5-Dimethyl Pyrazolate Complex for Quantification of Ethanol in Aqueous Solution", Evergreen, 7 (3) 404-08 (2020).

28) S Prashantha, RB Veeresha, SM Shashidhara, US Mallikarjun, and AG Shivasiddaramaiah, "A Study on Machining Characteristics of Al6061-Sic Metal Matrix Composite through Wire-Cut Electro Discharge Machining", Materials Today: Proceedings, 4 (10) 10779-85 (2017).

29) Chander Prakash, Sunpreet Singh, Manjeet Singh, Parvesh Antil, Abdul Azeez Abdu Aliyu, AM AbdulRani, and Sarabjeet S Sidhu, "Multi-Objective Optimization of Mwcnt Mixed Electric Discharge Machining of Al-30sic P Mmc Using Particle Swarm Optimization", Springer, 2018.

30) M Uthayakumar, K Vinoth Babu, S Thirumalai Kumaran, S Suresh Kumar, JT Winowlin Jappes, and TPD Rajan, "Study on the Machining of Al-Sic Functionally Graded Metal Matrix Composite Using Die-Sinking Edm", Particulate Science and Technology, 37 (1) 103-09 (2019).

31) PM Gopal, "Wire Electric Discharge Machining of Silica Rich E-Waste Crt and Bn Reinforced Hybrid Magnesium Mmc", Silicon, 11 (3) 1429-40 (2019).

32) Akash Gupta, 'Edm Parametric Study of Composite Materials: A' (Kyushu University, 2020).

33) TS Senthilkumar, and R Muralikannan, "Enhancing the Geometric Tolerance of Aluminium Hybrid Metal Matrix Composite Using Edm Process", Journal of the Brazilian Society of Mechanical Sciences and Engineering, 41 (1) 41 (2019).

34) Xia Zhao, Shuai Yuan, Zuquan Jin, Qingjun Zhu, Meng Zheng, Quantong Jiang, Huamiao Song, and Jizhou Duan, "Fabrication of Composite Coatings with Core-Shell Nanofibers and Their Mechanical 
Properties, Anticorrosive Performance, and Mechanism in Seawater", Progress in Organic Coatings, 149105893 (2020).

35) Chao Lei, Junkuo Gao, Wenjing Ren, Yuanbo Xie, Somia Yassin Hussain Abdalkarim, Shunli Wang, Qingqing Ni, and Juming Yao, "Fabrication of MetalOrganic Frameworks@ Cellulose Aerogels Composite Materials for Removal of Heavy Metal Ions in Water", Carbohydrate polymers, 205 35-41 (2019).

36) Xuyang Chu, Weihuang Zhuang, Wendong Xue, Xuejun Quan, Wei Zhou, and Ting Fu, "Electrolytic Removal of Recast Layers on Micro-Edm Microstructure Surfaces", The International Journal of Advanced Manufacturing Technology, 108 867-79 (2020).

37) Nan Wang, Xiao-Kun Ouyang, Li-Ye Yang, and Ahmed Mohamed Omer, "Fabrication of a Magnetic Cellulose Nanocrystal/Metal-Organic Framework Composite for Removal of $\mathrm{Pb}$ (Ii) from Water", ACS Sustainable Chemistry \& Engineering, 5 10447-58 (2017).

38) Bo Yu, Qin Huang, Yongkun Liu, and Guohua Jiang, "Fabrication of Composite Biofibres Based on Chitosan and Fluorinated Graphene for Adsorption of Heavy Metal Ions in Water", The Journal of The Textile Institute, 110 (3) 426-34 (2019).

39) Manu Srivastava, and Sandeep Rathee, "Optimisation of Fdm Process Parameters by Taguchi Method for Imparting Customised Properties to Components", Virtual and Physical Prototyping, 13 (3) 203-10 (2018).

40) Jaber E Abu Qudeiri, Aiman Zaiout, Abdel-Hamid I Mourad, Mustufa Haider Abidi, and Ahmed Elkaseer, "Principles and Characteristics of Different Edm Processes in Machining Tool and Die Steels", Applied Sciences, 10 (6) 2082 (2020).

41) A Perumal, A Azhagurajan, S Baskaran, R Prithivirajan, and P Narayansamy, "Statistical Evaluation and Performance Analysis of Electrical Discharge Machining (Edm) Characteristics of Hard Ti-6al-2sn-4zr-2mo Alloy", Materials Research Express, 6 (5) 056552 (2019).

42) Rajesh Bhuyan, Arun Parida, and Pritinika Behera, "Using Entropy Weight and over All Evaluation Criteria Optimize the Parameters in Edm of Al-20 Wt.\% Sicp Mmc", Available at SSRN 3735855 (2020).

43) Debabrata Dhupal, Subhashree Naik, and Sudhansu Ranjan Das, "Modelling and Optimization of Al-Sic Mmc through Edm Process Using Copper and Brass Electrodes", Materials Today: Proceedings, 5 (5) 11295-303 (2018).

44) Sabindra Kachhap, Abhishek Singh, and Sanoj Kumar, "Performance Evaluation of Different Electrode Geometries in Electric Discharge Drilling of Mmcs", Int J Mech Eng Rob Res, 8 (4) 531-35
(2019).

45) Tiago Czelusniak, Camila Fernandes Higa, Ricardo Diego Torres, Carlos Augusto Henning Laurindo, José Mário Fernandes de Paiva Júnior, Armin Lohrengel, and Fred Lacerda Amorim, "Materials Used for Sinking Edm Electrodes: A Review", Journal of the Brazilian Society of Mechanical Sciences and Engineering, 41 (1) 1-25 (2019).

46) Pushpendra Singh, Avanish Kumar Dubey, and Pankaj Kumar Shrivastava, 'Performance Evaluation of Electrical Discharge Abrasive Grinding Process Using Grinding Ratio', in 2019 8th International Conference System Modeling and Advancement in Research Trends (SMART) (IEEE, 2019), pp. 348-51.

47) Behnam Khosrozadeh, and Mohammadreza Shabgard, "Effects of Simultaneous Ultrasonic Vibration of Tool and Addition of Carbon Nanotube into the Dielectric in Edm Process on Machining Outputs and Surface Integrity of Ti-6al-4v Alloy", (2017).

48) Mohd Yunus Khan, and P Sudhakar Rao, "Optimization of Process Parameters of Electrical Discharge Machining Process for Performance Improvement", Int J Innov Technol Explor Eng, 8 (11) 3830-36 (2019).

49) Ravinder Kumar, and Inderdeep Singh, "A Modified Electrode Design for Improving Process Performance of Electric Discharge Drilling", Journal of Materials Processing Technology, 264 211-19 (2019).

50) Deepti Ranjan Sahu, and Amitava Mandal, "Critical Analysis of Surface Integrity Parameters and Dimensional Accuracy in Powder-Mixed Edm", Materials and Manufacturing Processes, 35 (4) 43041 (2020).

51) Mohammad Antar, Phillip Hayward, Justin Dunleavey, and Paul Butler-Smith, "Surface Integrity Evaluation of Modified Edm Surface Structure", Procedia Cirp, 68 308-12 (2018).

52) Qingyu Liu, Fazhan Yang, Shufeng Sun, Man Yang, and Jing Shao, "Surface Integrity of Micro Edm Surface Using Electrodes of Various Diameters", Coatings, 9 (12) 805 (2019).

53) Jonas Holmberg, Anders Wretland, Johan Berglund, and Tomas Beno, "Surface Integrity after Post Processing of Edm Processed Inconel 718 Shaft", The International Journal of Advanced Manufacturing Technology, 95 (5) 2325-37 (2018).

54) Thomas Simson, Andreas Emmel, Anja Dwars, and Juliane Böhm, "Residual Stress Measurements on Aisi 3161 Samples Manufactured by Selective Laser Melting", Additive Manufacturing, 17 183-89 (2017).

55) Caterina Casavola, Alberto Cazzato, Vincenzo Moramarco, and Giovanni Pappalettera, "Residual Stress Measurement in Fused Deposition Modelling Parts", Polymer Testing, 58 249-55 (2017).

56) Lin Cheng, and Albert To, "Part-Scale Build Orientation Optimization for Minimizing Residual 
Stress and Support Volume for Metal Additive Manufacturing: Theory and Experimental Validation", Computer-Aided Design, 113 1-23 (2019).

57) JR Hönnige, Paul A Colegrove, B Ahmad, ME Fitzpatrick, Supriyo Ganguly, TL Lee, and Stewart W Williams, "Residual Stress and Texture Control in Ti6al-4v Wire+ Arc Additively Manufactured Intersections by Stress Relief and Rolling", Materials \& Design, 150 193-205 (2018).

58) JJ Yan, DL Zheng, HX Li, X Jia, JF Sun, YL Li, M Qian, and M Yan, "Selective Laser Melting of H13: Microstructure and Residual Stress", Journal of Materials Science, 52 (20) 12476-85 (2017).

59) Abdul Khadar Syed, Bilal Ahmad, Hua Guo, Thays Machry, David Eatock, Jonathan Meyer, Michael E Fitzpatrick, and Xiang Zhang, "An Experimental Study of Residual Stress and Direction-Dependence of Fatigue Crack Growth Behaviour in as-Built and Stress-Relieved Selective-Laser-Melted Ti6al4v", Materials Science and Engineering: A, 755 246-57 (2019).

60) Haohui Xin, and Milan Veljkovic, "Residual Stress Effects on Fatigue Crack Growth Rate of Mild Steel S355 Exposed to Air and Seawater Environments", Materials \& Design, 193108732 (2020).

61) Alessandro Salmi, and Eleonora Atzeni, "Residual Stress Analysis of Thin Alsi10mg Parts Produced by Laser Powder Bed Fusion", Virtual and Physical Prototyping, 15 (1) 49-61 (2020).

62) Jamison L Bartlett, Brendan P Croom, Jeffrey Burdick, Daniel Henkel, and Xiaodong Li, "Revealing Mechanisms of Residual Stress Development in Additive Manufacturing Via Digital Image Correlation", Additive Manufacturing, 22 1-12 (2018).

63) Zhaopeng Tong, Xudong Ren, Jiafei Jiao, Wangfan Zhou, Yunpeng Ren, Yunxia Ye, Enoch Asuako Larson, and Jiayang Gu, "Laser Additive Manufacturing of Fecrcomnni High-Entropy Alloy: Effect of Heat Treatment on Microstructure, Residual Stress and Mechanical Property", Journal of Alloys and Compounds, 785 1144-59 (2019).

64) A Magnier, T Wu, SR Tinkloh, T Tröster, B Scholtes, and T Niendorf, "On the Reliability of Residual Stress Measurements in Unidirectional Carbon Fibre Reinforced Epoxy Composites", Polymer Testing, 97 107146 (2021).

65) Tatiana Mishurova, Sandra Cabeza, Katia Artzt, Jan Haubrich, Manuela Klaus, Christoph Genzel, Guillermo Requena, and Giovanni Bruno, "An Assessment of Subsurface Residual Stress Analysis in Slm Ti-6al-4v", Materials, 10 (4) 348 (2017).

66) Muhammad P Jahan, "Electro-Discharge Machining (Edm)", Modern Manufacturing Processes 377-409 (2019).

67) Ramesh Rudrapati, and Lakhan Rathod, 'Effects of
Wire-Edm Machining Variables on Surface Roughness of D2 Steel Material', in Materials Science Forum (Trans Tech Publ, 2019), pp. 656-61.

68) Asarudheen Abdudeen, Jaber E Abu Qudeiri, Ansar Kareem, Thanveer Ahammed, and Aiman Ziout, "Recent Advances and Perceptive Insights into Powder-Mixed Dielectric Fluid of Edm", Micromachines, 11 (8) 754 (2020).

69) Moritz Wiessner, Felipe TB Macedo, CP Martendal, Fredy Kuster, and Konrad Wegener, "Fundamental Investigation of Edm Plasmas, Part I: A Comparison between Electric Discharges in Gaseous and Liquid Dielectric Media", Procedia CIRP, 68 330-35 (2018)

70) YL Teng, L Li, W Zhang, N Wang, CC Feng, and JH Ren, "Machining Characteristics of Pcd by Edm with $\mathrm{Cu}-\mathrm{Ni}$ Composite Electrode", Materials and Manufacturing Processes, 35 (4) 442-48 (2020).

71) Felipe TB Macedo, Moritz Wiessner, GC Bernardelli, Fredy Kuster, and Konrad Wegener, "Fundamental Investigation of Edm Plasmas, Part Ii: Parametric Analysis of Electric Discharges in Gaseous Dielectric Medium", Procedia CIRP, 68 336-41 (2018).

72) Sumit Bhowmik, and Divya Zindani, "Overview of Hybrid Micro-Manufacturing Processes", Springer, 2019.

73) Zhaojun Kou, and Fuzhu Han, "Machining Characteristics and Removal Mechanisms of Moving Electric Arcs in High-Speed Edm Milling", Journal of Manufacturing Processes, 32 676-84 (2018).

74) AM Efendee, A Azhari, AR Hasnain, S Zainal Ariffin, and M Mukhtar, 'Investigation of Magnetic Field Effect on Mrr, Ewr and Surface Roughness During Edm of Aisi420 Tool Steel', in IOP Conference Series: Materials Science and Engineering (IOP Publishing, 2021), p. 012018.

75) V Srinivas Viswanth, $R$ Ramanujam, and G Rajyalakshmi, "Performance Study of Eco-Friendly Dielectric in Edm of Aisi 2507 Super Duplex Steel Using Taguchi-Fuzzy Topsis Approach", International Journal of Productivity and Quality Management, 29 (4) 518-41 (2020).

76) S Debnath, RN Rai, and GRK Sastry, "A Study of Multiple Regression Analysis on Die Sinking Edm Machining of Ex-Situ Developed Al-4.5 Cu-Sic Composite", Materials Today: Proceedings, 5 (2) 5195-201 (2018). 